\title{
CONTROLLABILITY OF NONAUTONOMOUS SEMILINEAR INTEGRODIFFERENTIAL INCLUSIONS IN BANACH SPACES
}

\author{
Yong-Kui CHANG AND Li-MeI QI
}

\begin{abstract}
In this paper, we establish a sufficient condition for the controllability of nonautonomous integrodifferential inclusions with nonlocal conditions in Banach spaces. The approach used is the Sadovskii's fixed point theorem with the theory of resolvent operators.
\end{abstract}

Mathematics subject classification (2000): 34A60, 34A37.

Key words and phrases: nonautonomous integrodifferential inclusions, controllability, fixed point.

\section{REFERENCES}

[1] K. Balachandran, J. P. DAUER, Controllability of nonlinear systems in Banach spaces: a survey, J. Optim. Theory Appl., 115, (2002), 7-28.

[2] M. Benchohra, S. K. NTOUYAS, Controllability for functional differential and integrodifferential inclusions in Banach spaces, J. Optim. Theory Appl., 113, (2002),449-472.

[3] M. Benchohra, E. P. GATSORI AND S. K. NTOUYAS, Controllability results for semilinear evolution inclusions with nonlocal conditions, J. Optim. Theory Appl., 118, (2003), 493-513.

[4] A. Bressan, G. Colombo, Existence and selections of maps with decomposable values, Studia Math., 90, (1988), 69-86.

[5] K. DeimLing, Multivalued Differential Equations, De Gruyter, Berlin, 1992.

[6] M. FRIGON, Theoremes d'existence de solutions d'inclusions differentielles, Topological Methods in Differential Equations and Inclusions (edited by A.Granas and M. Frigon), NANO ASI Series C, Vol.472, Kluwer Acad. Publ., Dordrecht, (1995), 51-87.

[7] M. GuO, X. XUE AND R. LI, Controllability of impulsive evolution inclusions with nonlocal conditions, J. Optim. Theory Appl., 120, (2004), 355-374.

[8] R. GRIMMER, Resolvent operators for integral equations in a Banach space, Trans. Amer. Math. Soc., 273, (1982), 333-349.

[9] S. Hu, N. PAPAGEORGIOU, Handbook of multivalued analysis, Kluwer, Dordrecht, Boston, 1997.

[10] G. LI, X. XUE, Controllability of evolution inclusions with nonlocal conditions, Appl. Math. Comput., 141, (2003), 375-384.

[11] J. LiU, K. EZZNBI, Nonautonomous integrodifferential equations with nonlocal conditions, J. Integral Equa. Appl., 15, (2003), 79-93.

[12] M. D. QUINN, N. CARMICHAEL, An approach to nonlinear control problem using fixed point methods, degree theory and pseudo-inverses, Numer. Funct. Anal. Optim., 23, (1991), 109-154.

[13] B. N. SADOVSKII, On a fixed point principle, Func. Anal. Appl., 1, (1967), 74-76.

[14] K. YosidA, Functional Analysis, 6th edn. Springer-Verlag, Berlin, 1980. 